\title{
How to prevent adverse events of vascular stapling in thoracic surgery: recommendations based on a clinical and experimental study
}

\author{
Nahoko Shimizu, Yugo Tanaka, Takeshi Okamoto, Takefumi Doi, Daisuke Hokka, Yoshimasa Maniwa \\ Division of Thoracic Surgery, Kobe University Graduate School of Medicine, Kobe, Japan \\ Contributions: (I) Conception and design: Y Tanaka, N Shimizu; (II) Administrative support: Y Maniwa; (III) Provision of study materials or patients: \\ T Okamoto, N Shimizu; (IV) Collection and assembly of data: T Doi, D Hokka, N Shimizu; (V) Data analysis and interpretation: Y Tanaka, N \\ Shimizu; (VI) Manuscript writing: All authors; (VII) Final approval of manuscript: All authors. \\ Correspondence to: Yugo Tanaka. Division of Thoracic Surgery, Kobe University Graduate School of Medicine, 7-5-2 Kusunoki-cho, Chuou-ku, Kobe, \\ Hyogo 650-0017, Japan. Email: tanakay@med.kobe-u.ac.jp.
}

\begin{abstract}
Background: Advances in the development of staplers for pulmonary vessels have contributed to safe and convenient procedures in thoracic surgery. However, adverse events (AEs) can occur during vascular stapling and cause fatal hemorrhage. We aimed to assess the risk level of using the vessel stapling procedure to reduce such AEs.

Methods: First, an animal experiment using pig cardiopulmonary blocks was conducted. Pulmonary arteries were closed with staplers under stressful conditions such as lifting or twisting; vessel stump endurance was analyzed through different methods. Second, AEs associated with clinical stapler use for pulmonary vessels were retrospectively reviewed by studying clinical videos of 263 patients.

Results: In the animal experiment, the pressure resistance was significantly lower in the twisted group than in the no strain group (no strain vs. lifting: $\mathrm{P}=0.2008$, no strain $v$ s. twisting: $\mathrm{P}=0.002$, no strain $v s$. twisting and lifting: $\mathrm{P}<0.0001)$. Regarding clinical stapler use, 754 staplers were used against the vessels. AEs occurred in 9 cases, and 7 cases were suspected to be caused by vessel tension.

Conclusions: The pulmonary vessel stapling causes stress due to twisting and lifting that decreased stump durability. Avoiding such stress when using stapler for vessels leads to a safer thoracic surgery.
\end{abstract}

Keywords: Mechanical stapler; pulmonary artery; thoracoscopy

Submitted Aug 15, 2018. Accepted for publication Oct 25, 2018.

doi: $10.21037 /$ jtd.2018.11.14

View this article at: http://dx.doi.org/10.21037/jtd.2018.11.14

\section{Introduction}

Video-assisted thoracic surgery (VATS) is becoming increasingly popular because of advancements in surgical devices and techniques; it enables postoperative pain reduction and quicker functional and social recovery than conventional thoracotomy (1-4). The use of mechanical staplers for pulmonary vessels and bronchi can contribute to safer and simpler operative procedures in VATS.

Staplers have been used in thoracoscopy since the 1990s, initially for the lung parenchyma or tissue and bronchi and gradually for blood vessels $(5,6)$. As staplers improved, procedures using staplers are regarded safe and is now widely used for thoracic surgery $(7,8)$. However, occasionally, adverse events (AEs) of vascular stapling such as oozing and rupture of the vessel stumps occur (9-12). Given the nature of the vascular anatomy and physiology of the chest, combined with high blood flow in a low-pressure system, unexpected injury can lead to fatal hemorrhage within moments (13). Since reducing such AEs as much as possible leads to an improvement in the quality of surgery, we consider that improvement of the procedure is also important from this point of view. Although a few reports 

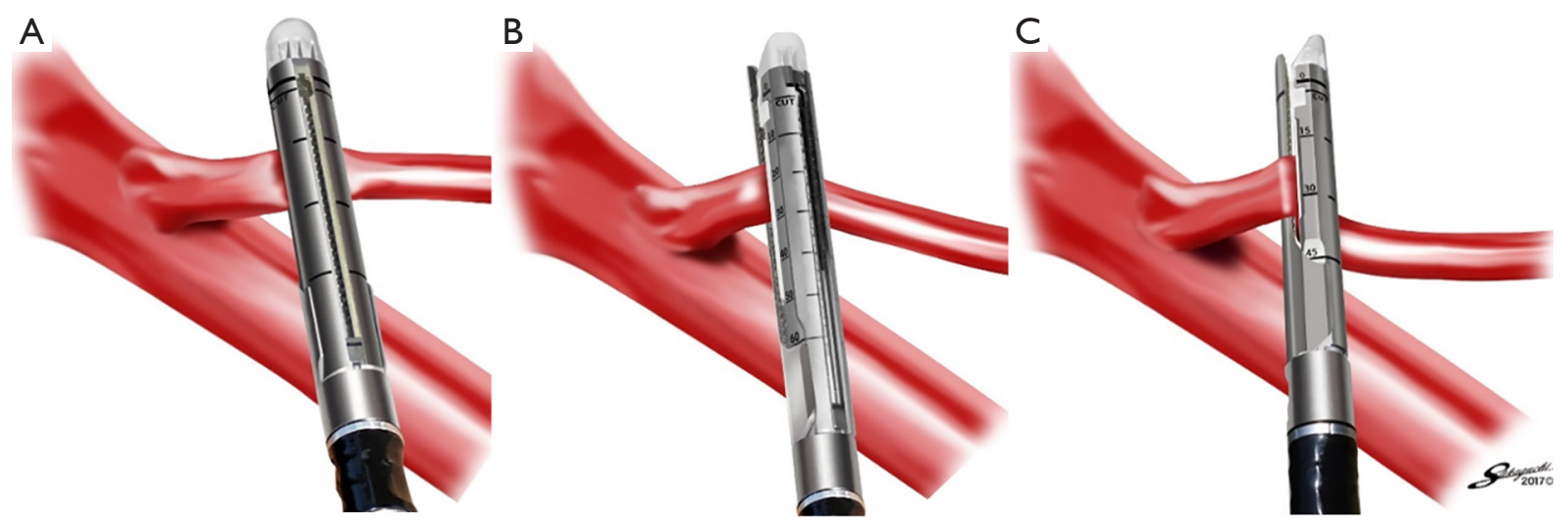

Figure 1 Stress to the vessels on firing. (A) Lifting; (B) twisting; (C) lifting and twisting.

have mentioned stapling (7), to our knowledge, no report has described the association between vessel stress due to mechanical staplers and endurance of vessel stumps. In this study, we conducted a durability test for vessel stumps using an animal model to investigate the association between vessel stress caused by staplers and stump endurance. Then, we examined the clinical outcomes of staple use in our previous surgical cases.

\section{Methods}

First, to examine the efficient use of mechanical staplers for pulmonary vessels, an animal experiment using pig-excised cardiopulmonary blocks was conducted. Vessel stump strength was assessed by pressure test and by checking the staple lines for deformation. Second, to verify the results of our experimental model, AEs associated with clinical stapler use for pulmonary vessels were explored by studying clinical videos retrospectively. This study was approved by the Institutional Review Board of Kobe University, and written informed consent was obtained from each participant (approval no. 180062).

\section{Experimental protocols}

\section{Animal experiment}

The left pulmonary arteries were used from the excised cardiopulmonary blocks of pigs. The arterial branch diameter was measured before firing; branches with $\geq 5 \mathrm{~mm}$ diameter were selected for the pressure test. The type of stapler used for our experiment was the Powered Echelon flex seven with a white cartridge (35-mm staple leg length) produced by Ethicon Endo-Surgery (Cincinnati, OH, USA).
During surgery, twisting and lifting were assumed as possible situations causing vascular dissection. Comparisons were made under the following four conditions as the stress applied to the vessel on firing of mechanical staplers: Group A, no strain; Group B, only lifting (Figure 1A); Group C, only twisting (Figure 1B); and Group D, lifting and twisting (Figure 1C).

After vessel stapling, a pressure test was conducted to examine stump endurance. The pulmonary artery (PA) was cut from the cardiopulmonary blocks at the base of the main trunk, and the central side of the PA trunk was tied to the cannula with a pressure meter. The PA was filled with red-colored normal saline solution using syringe. The pressure was measured at the point of fluid leakage from the stumps (5). The pressure in the system was also monitored visually and recorded with more than two doctors to ensure accurate readings. After the pressure test, the staple line was inspected for deformation, and the number of deformed staples was compared in each group.

\section{AEs associated with clinical stapler use}

Between January 2016 and December 2017, 263 patients underwent thoracoscopic anatomical lung resection in our institution. Surgical video was taken for recording purposes in all cases, and video reviews were performed for all patients to reveal the possible cause for AEs. Stump rupture, technical vascular injury, and oozing that needed hemostasis agents, such as fibrin sealant patch or direct suturing, were defined as AEs concerning intraoperative stapling. Oozing was defined as small bleeding from the stumps or points of the staples, and technical vascular injury was defined as bleeding that occurred before the stapling process due to technical failure. Details of bleeding situation were 


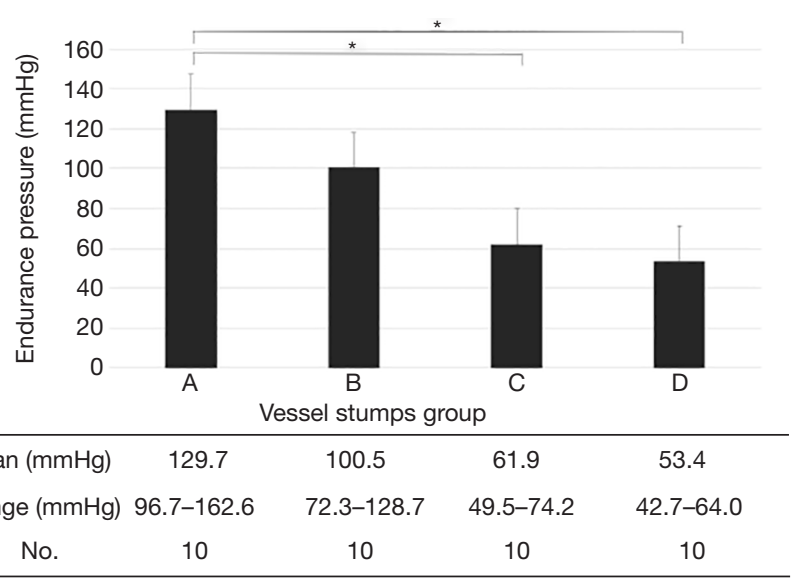

Figure 2 Pressure resistance of the vessel stumps in each group. The pressure was significantly lower in the twisted group (C,D) than in the no strain group $(\mathrm{A})\left({ }^{*} \mathrm{P}<0.01\right)$.
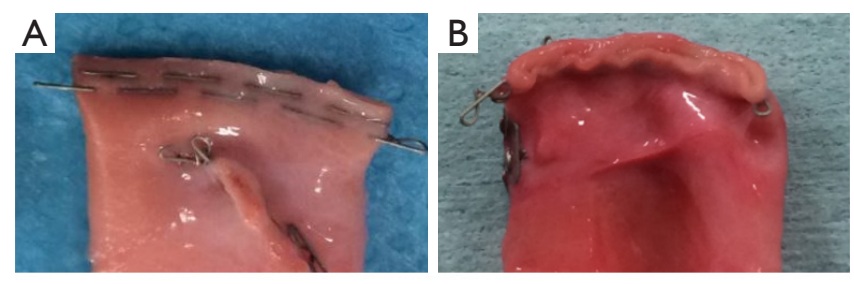

$\mathrm{C}_{4}$

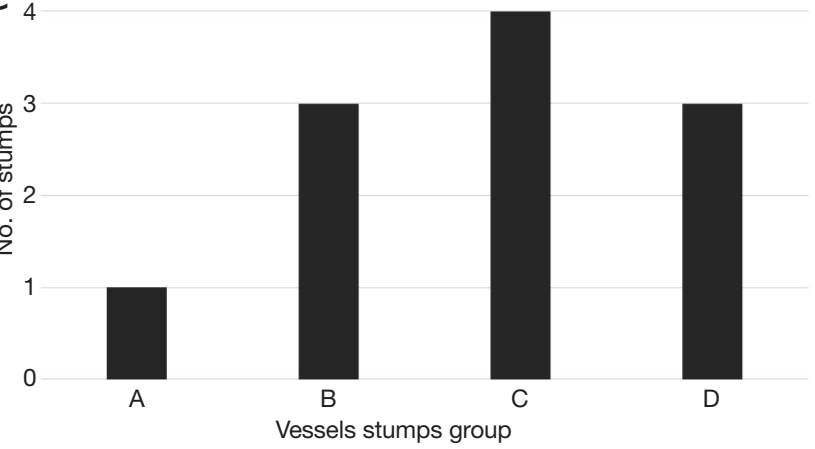

Figure 3 Shape of the staple lines. They were evaluated macroscopically and categorized into two groups. (A) Optimally formed; (B) deformed; (C) number of the deformed staple lines in each group.

confirmed by surgical video, and patient characteristics between those with and without AEs were compared.

\section{Statistical analysis}

The maximum pressure of the stump in each group was compared using the Tukey-Kramer test. Patient characteristics were analyzed using Student's $t$-test for continuous variables and $\chi^{2}$ test for categorical data. All analyses used JMP 8.0 software (SAS Inc., Cary, NC, USA). A P value less than 0.05 was considered statistically significant.

\section{Results}

\section{Animal experiment}

Ten PAs were examined in each group, and there were no differences in the vessel diameter among the groups. There was no difference in pressure resistance caused by vessel diameter. Pressure resistance was significantly lower in the twisted group than in the no strain group (A vs. B: $\mathrm{P}=0.2008$, A vs. $\mathrm{C}: \mathrm{P}=0.0002$, A vs. $\mathrm{D}: \mathrm{P}<0.0001$; Figure 2). Pressure resistance was not related to the vessel diameter. Regarding the shape of the stumps, deformation of the staple line tended to occur under stressed conditions (A: 1, B: 3, C: 4, D: 3) (Figure 3).

\section{AEs associated with clinical stapler use}

All staplers used in this study were manufactured by Covidien (Mansfield, MA, USA) or Ethicon Endo-Surgery (Cincinnati, OH, USA). A total of 754 staplers were used for pulmonary vessels, and nine AEs (1.19\%) were judged to be related to stapling (Table 1). All AEs were oozing of PA, there was no fatal bleeding, including rupture and technical vascular injury, and there were no conversions from VATS to thoracotomy. The estimated factors that cause AEs were vessel stress: 7 twisting and lifting during vascular dissection, 1 hematoma formation on exfoliation, and 1 inapplicable diameter of the vessels. The brand of the mechanical staplers and vessel diameter did not influence the occurrence of AEs, although accurate measurement of vessel diameter was impossible in our clinical study. We examined the patient characteristics of cases with and without AEs, and compared patient's age, sex, smoking status, presence or absence of diabetes, hypertension, chronic obstructive pulmonary disease, but no difference was found between the two groups (Table 2).

\section{Discussion}

The safety of VATS has been discussed since the 1990s, which has given rise to numerous considerations. Many reports have demonstrated the efficacy and safety of VATS compared with thoracotomy. Kirby et al. (14) reported 
Table 1 Details of adverse events of the pulmonary vascular stapling

\begin{tabular}{lcccllc}
\hline No & Vessel & Disease & Procedure & AEs & Type of hemostasis & Occasion of AEs \\
\hline 1 & PA & LK & L & Oozing & Fibrin sealant patch & Twisting \\
2 & PA & LK & L & Oozing & Fibrin sealant patch & Twisting \\
3 & PA & NTM & L & Oozing & Fibrin sealant patch & Twisting \\
4 & PA & LK & S & Oozing & Fibrin sealant patch & Inapplicable diameter \\
5 & PA & LK & L & Oozing & Fibrin sealant patch & Lifting \\
7 & PA & LK & L & Oozing & Fibrin sealant patch & Twisting + lifting \\
9 & PA & LK & L & Oozing & Fibrin sealant patch & Twisting \\
\hline
\end{tabular}

AEs, adverse events; PA, pulmonary artery; LK, lung cancer; L, lobectomy; NTM, non-tuberculous mycobacterium; S, segmentectomy.

Table 2 Patient characteristics based on clinical data

\begin{tabular}{lccc}
\hline Characters & AEs $(n=9)$ & Non-AEs $(n=254)$ & $P$ value \\
\hline $\begin{array}{l}\text { Age, mean [range] } \\
\text { (years) }\end{array}$ & $69.0[45-85]$ & $69.2[37-88]$ & 0.94 \\
$\begin{array}{l}\text { Gender, n (\%) } \\
\quad \text { Male }\end{array}$ & $5(55.6)$ & $150(59.1)$ & 0.834 \\
Female & $4(44.4)$ & $104(40.9)$ & \\
$\begin{array}{l}\text { Smoking states, mean } \\
\text { (pack-years) }\end{array}$ & 27.9 & 31.5 & 0.759 \\
Diabetes, n (\%) & $1(11.1)$ & $49(19.3)$ & 0.539 \\
Hypertension, n (\%) & $5(55.6)$ & $107(42.1)$ & 0.355 \\
COPD, n (\%) & $4(44.4)$ & $63(24.8)$ & 0.184 \\
\hline
\end{tabular}

AEs, adverse events; COPD, chronic obstructive pulmonary disease.

a small-scale randomized controlled trial comparing the results of standard thoracotomy lobectomy with VATS lobectomy in clinical stage I non-small cell lung cancer. There was no difference between the two groups in terms of surgical results, such as surgery time, bleeding volume, and 5 -year survival rate. Paul et al. (15) reported a comparison of VATS and open thoracotomy based on the Society of Thoracic Surgeons (STS) database as a multicenter analysis; no difference was found in the mortality rate, and the incidence of complications was significantly lower with VATS. There are several reports on the low perioperative complication rate of VATS (16-18), and VATS is now recognized as safe as thoracotomy and is less invasive.
However, VATS lobectomy occasionally requires, for various reasons, emergency conversion to thoracotomy. Several investigators have reported the conversion rates as $2-14 \%(13,19-23)$. The most common causes of conversion were hemorrhage, oncologic causes, and lymph node involvement. Conversion due to hemorrhage can be fatal, as it takes time to convert to open thoracotomy; therefore, it is necessary to prevent conversion due to hemorrhage as much as possible.

AEs related to mechanical stapler use are occasionally reported and can be a serious situation. Asamura et al. (8) reported stapling failure in 1 of 842 mechanical stapler divisions $(0.1 \%)$, and the reason for the failure was misalignment of a cartridge. Szwerc et al. (10) reported 7 vascular complications in a total of 2,548 vascular staplings, which included 5 minor intimal fractures, 1 posterior segmental arterial avulsion, and 1 staple misfiring, with an $\mathrm{AE}$ rate during stapler application of $0.27 \%$. They considered that all injuries were related to excessive traction placed on PA branches when inserting or firing the stapler. Yano et al. (9) reported AEs of pulmonary vascular stapling in a multi-institutional retrospective study and analyzed the details of AEs. Nine AEs were judged to be related to stapling in 3,393 vascular staplings $(0.27 \%)$, and AEs in the PA were seen more frequently than those in the pulmonary vein for intraoperative stapling.

To prevent such AEs, the vessel should be closed at an untensioned angle, but there is no report on the association between vessel stress due to staplers and stump endurance. In our experimental model, decreased stump durability and many deformed staples were observed in the PAs that were 
cut under stress conditions, especially twisting. Under stress conditions such as twisting and lifting, curvature occurs in the shape of the staple line, and the stumps tend to break down easily. Of course, the normal value of PA pressure is $15-30 \mathrm{mmHg}$, and high pressure, as in the experiment, does not actually occur.

However, some reports showed that the rupture of pulmonary vessels occurred in clinical situation (9) have been caused by the stress to the vessels at firing. We believe that stabilization of the blood vessel stump is necessary because unexpected external forces could act on the staple line during or after operation.

When examining clinical videos of our series, the frequency of $\mathrm{AE}$ was $1.19 \%$ (8-10), which was higher than that seen in a previous report. This seems to be due to the inclusion of quite minute bleeding. All AEs were oozing from the PA, and we did not encounter severe events like rupture and stapling failure. Regarding the stress to the blood vessel in 7 cases, twisting was observed in 4 cases, lifting in 2 cases, and twisting and lifting in 1 case. Even in clinical use, the durability of the stump was decreased in cases where twisting was applied; this supports the findings in the animal experiment.

In clinical situations, it is sometimes impossible to insert a stapler at a good angle because the thoracic shape, chest wall thickness, and intercostal space width vary from patient to patient. Therefore, traction or twisting of the vessels is often needed to obtain an optimal surgical view when the stapler approaches the vessels. Even when stress due to traction is unavoidable, it is important to reduce the stress to the vessels, at least on firing. Although VATS with a small number of ports is possible, 4-port VATS was performed in our institution because we believe that the angle of which the stapler approaches the vessels is important. To avoid AEs, we definitely avoided twisting even if pulling is permitted, and we are willing to add ports when strong tension is likely to occur.

Regarding the association between the type of cartridge and AEs of stapling in pulmonary vessels, there was no difference between the type of cartridge (white $v s$. gray, 4-row vs. 6-row) in several reports $(9,24)$. Although only white and 4-row cartridges were used in our experiment model, there seemed to be no significant differences between the type of cartridge and AEs of stapling because AEs were seen in both types of cartridge in our clinical situation.

The present study was limited due to the use of pigexcised cardiopulmonary blocks. It should be done in vivo if possible, but we believed the vessels used in our study could simulate an in vivo situation because we used fresh tissues with sufficient vascular strength and elasticity. It is more difficult to examine human living lungs, but some clinical prospects were obtained through examination of clinical videos. Another limitation includes the small number of samples. Additional studies are needed to determine the clinical relevance of our findings.

In conclusion, the stress of the pulmonary vessels such as twisting and lifting decreased the durability of the stumps. Although there is a restriction in the approach of the automatic suturing device for vessels, reduction of stress on vessels by firing as little as possible will enable safer surgeries.

\section{Acknowledgements}

None.

\section{Footnote}

Conflicts of Interest: The authors have no conflicts of interest to declare.

Ethical Statement: This study was approved by the Institutional Review Board of Kobe University, and written informed consent was obtained from each participant (approval no. 180062).

\section{References}

1. Atkins BZ, Harpole DH, Mangum JH, et al. Pulmonary segmentectomy by thoracotomy or thoracoscopy: reduced hospital length of stay with a minimally-invasive approach. Ann Thorac Surg 2007;84:1107-12.

2. Seder CW, Hanna K, Lucia V, et al. The safe transition from open to thoracoscopic lobectomy: a 5 -year experience. Ann Thorac Surg 2009;88:216-25.

3. Daniels LJ, Balderson SS, Onaitis MW, et al. Thoracoscopic Lobectomy: A Safe and Effective Strategy for Patients With Stage I Lung Cancer. Ann Thorac Surg 2002;74:860-4.

4. Nagahiro I, Andou A, Aoe M, et al. Pulmonary function, postoperative pain, and serum cytokine level after lobectomy: a comparison of VATS and conventional procedure. Ann Thorac Surg 2001;72:362-5.

5. Graeber GM, Collins JJ Jr, DeShong JL,et al. Are sutures better than staples for closing bronchi and 
pulmonary vessels? Ann Thorac Surg 1991;51:901-4; discussion 904-5.

6. Acuff TE, Mack MJ, Landreneau RJ, et al. Role of mechanical stapling devices in thoracoscopic pulmonary resection. Ann Thorac Surg 1993;56:749-51.

7. Sugarbaker DJ, Mentzer SJ. Improved Technique for Hilar Vascular Stapling. Ann Thorac Surg 1992;53:165-6.

8. Asamura H, Suzuki K, Kondo H, et al. Mechanical vascular division in lung resection. Eur J Cardiothorac Surg 2002;21:879-82.

9. Yano M, Takao M, Fujinaga T, et al. Adverse events of pulmonary vascular stapling in thoracic surgery. Interact Cardiovasc Thorac Surg 2013;17:280-4.

10. Szwerc MF, Landreneau RJ, Santos RS, et al. Minithoracotomy combined with mechanically stapled bronchial and vascular ligation for anatomical lung resection. Ann Thorac Surg 2004;77:1904-9.

11. Craig SR, Walker WS. Potential Complications of Vascular Stapling in Thoracoscopic Pulmonary Resection. Ann Thorac Surg 1995;59:736-7; discussion 737-8.

12. Gossot D, Merlusca G, Tudor A, et al. Pitfalls related to the use of endostaplers during video-assisted thoracic surgery. Surg Endosc 2009;23:189-92.

13. Safdie FM, Sanchez MV, Sarkaria IS. Prevention and management of intraoperative crisis in VATS and open chest surgery: how to avoid emergency conversion. J Vis Surg 2017;3:87.

14. Kirby TJ, Mack MJ, Landreneau RJ, et al. Lobectomy-video-assisted thoracic surgery versus muscle-sparing thoracotomy. A randomized trial. J Thorac Cardiovasc Surg 1995;109:997-1001; discussion 1001-2.

15. Paul S, Altorki NK, Sheng S, et al. Thoracoscopic lobectomy is associated with lower morbidity than open lobectomy: a propensity-matched analysis from the STS database. J Thorac Cardiovasc Surg 2010;139:366-78.

Cite this article as: Shimizu N, Tanaka Y, Okamoto T, Doi T, Hokka D, Maniwa Y. How to prevent adverse events of vascular stapling in thoracic surgery: recommendations based on a clinical and experimental study. J Thorac Dis 2018;10(12):64666471. doi: $10.21037 /$ jtd.2018.11.14
16. Yan TD, Black D, Bannon PG, et al. Systematic review and meta-analysis of randomized and nonrandomized trials on safety and efficacy of video-assisted thoracic surgery lobectomy for early-stage non-small-cell lung cancer. J Clin Oncol 2009;27:2553-62.

17. Villamizar NR, Darrabie MD, Burfeind WR, et al. Thoracoscopic lobectomy is associated with lower morbidity compared with thoracotomy. J Thorac Cardiovasc Surg 2009;138:419-25.

18. McKenna RJ, Houck W, Fuller CB. Video-assisted thoracic surgery lobectomy: experience with 1,100 cases. Ann Thorac Surg 2006;81:421-5.

19. Sawada S, Komori E, Yamashita M. Evaluation of videoassisted thoracoscopic surgery lobectomy requiring emergency conversion to thoracotomy. Eur J Cardiothorac Surg 2009;36:487-90.

20. Decaluwe H, Petersen RH, Hansen H, et al. Major intraoperative complications during video-assisted thoracoscopic anatomical lung resections: an intention-totreat analysis. Eur J Cardiothorac Surg 2015;48:588-98.

21. Puri V, Patel A, Majumder K, et al. Intraoperative conversion from video-assisted thoracoscopic surgery lobectomy to open thoracotomy: a study of causes and implications. J Thorac Cardiovasc Surg 2015;149:5561, 62.e1.

22. Jones RO, Casali G, Walker WS. Does failed video-assisted lobectomy for lung cancer prejudice immediate and longterm outcomes? Ann Thorac Surg 2008;86:235-9.

23. Li Y, Wang J, Yang F, et al. Indications for conversion of thoracoscopic to open thoracotomy in video-assisted thoracoscopic lobectomy. ANZ J Surg 2012;82:245-50.

24. Ng CS, Pickens A, Siegel JM, et al. A novel narrow profile articulating powered vascular stapler provides superior access and haemostasis equivalent to conventional devicest. Eur J Cardiothorac Surg 2016;49 Suppl 1:i73-8. 